Assessing Urban Transport Systems through the Lens of Individual Behavior: Shenzhen and Hong Kong

Shengyuan ZHANG, Jimin ZHAO

HKUST IEMS Working Paper No. 2015-34

June 2016

HKUST IEMS working papers are distributed for discussion and comment purposes. The views expressed in these papers are those of the authors and do not necessarily represent the views of HKUST IEMS.

More HKUST IEMS working papers are available at: http://iems.ust.hk/WP 


\title{
Assessing Urban Transport Systems through the Lens of Individual Behavior: Shenzhen and Hong Kong
}

Shengyuan ZHANG, Jimin ZHAO

HKUST IEMS Working Paper No. 2015-34

June 2016

\begin{abstract}
This study aims to understand the existing urban passenger transport system in Hong and Shenzhen from the perspective of human travel behavior, examining closely what policy and individual factors influence individual travel behavior in the two cities. The research is based on comparisons drawn from household and individual travel surveys conducted in Shenzhen in 2014 and in Hong Kong in 2002 and 2011. Hong Kong operates a more efficient urban passenger transport system than Shenzhen in terms of prioritizing use of public transport and restricting the use of cars. However, due to lack of strong government leadership, Hong Kong lags behind Shenzhen in promoting EVs. Both cities have had little success promoting nonmotorized transportation because of the greater appeal of alternative transportation modes.
\end{abstract}

\section{Authors' contact information}

Shengyuan Zhang

Division of Social Science

Hong Kong University of Science and Technology

E: szhangah@ust.hk

Click here to enter text.

Jimin Zhao

Division of Social Science

Hong Kong University of Science and Technology

E: jiminzhao@ust.hk 


\title{
Assessing Urban Transport Systems through the Lens of Individual Behavior: Shenzhen and Hong Kong
}

\author{
Jimin Zhao and Shengyuan Zhang*
}

\begin{abstract}
This study aims to understand the existing urban passenger transport system in Hong and Shenzhen from the perspective of human travel behavior, examining closely what policy and individual factors influence individual travel behavior in the two cities. The research is based on comparisons drawn from household and individual travel surveys conducted in Shenzhen in 2014 and in Hong Kong in 2002 and 2011. Hong Kong operates a more efficient urban passenger transport system than Shenzhen in terms of prioritizing use of public transport and restricting the use of cars. However, due to lack of strong government leadership, Hong Kong lags behind Shenzhen in promoting EVs. Both cities have had little success promoting nonmotorized transportation because of the greater appeal of alternative transportation modes.
\end{abstract}

*Jimin Zhao (jiminzhao@,ust.hk) is Associate Professor of Social Science, HKUST. Shengyuan Zhang (szhangah@ust.hk) is Ph.D. candidate in Social Science, HKUST. The authors acknowledge support from the Public Policy Research Funding Scheme of the Hong Kong Research Grants Council (HKUST6006-PPR-12) and the support from Hong Kong Transport Department for access to the data collected by the Travel Characteristics Survey 2002 and 2011 (TCS 2002 and TCS 2011). 


\section{Assessing Urban Transport Systems through the Lens of Individual Behavior: \\ Shenzhen and Hong Kong}

\section{Introduction}

Mobility is one of the most fundamental challenges facing cities, as transport provides one of the essential infrastructures for development. But it also directly affects the economic efficiency and the well-being of city inhabitants through access to housing, work, education, health care, and other amenities. Transport also impacts environmental and health outcomes through traffic congestion, air pollution, high noise levels, high numbers of accidents, and carbon emissions.

Cities are the center of energy consumption and emissions; they account for 75 per cent of global energy consumption and nearly 80 percent of greenhouse gas emissions (World Bank 2010). Achieving sustainable transport is one of the most fundamental challenges in realizing greater carbon efficiency at the city level. Internationally, the transport sector uses a large share of oil resources, accounting for over $61 \%$ of total oil demand in 2008 (IEA 2010). Transport-related $\mathrm{CO}_{2}$ emissions account for between $15 \%$ and $40 \%$ of total city $\mathrm{CO}_{2}$ emissions, mainly from road transport, and in many developing countries account for the greatest share of the increase in carbon emissions because individuals aspire to own their own vehicles. Traffic volumes continue to rise in most cities and the transport sector has continued to be the most difficult sector within which to reduce $\mathrm{CO}_{2}$ emissions for both developed economies with well-developed transport systems and emerging economies with underdeveloped transport systems (Hickman and Banister 2007; Hickman, Ashiru and Banister 2009a, 2009b, 2010).

In many large cities in developed economies, e.g., London, $\mathrm{CO}_{2}$ emissions from the transport sector continues to increase and the transport sector is a main contributor to energy 
consumption and carbon emissions (Hickman and Banister, 2007; Banister 2007). These cities face even greater challenges because it is more costly to switch away from existing transport infrastructure and residents are accustomed to traditional transport systems. Cities in emerging economies have an urgent need to tackle sustainable transport on a grand scale in order to create pathways towards sustainability. Such cities are growing very rapidly and more and more people, especially the younger generation, pursue modern lifestyles that are high in energy consumption and $\mathrm{CO}_{2}$ emissions (Dimitriou 2006). In China, three hundred million Chinese rural dwellers will move to cities over the next twenty years (Woetzel, Mendonca, and et al 2009). More new vehicles are sold in China than anywhere else in the world, which is a primary driving force behind China's increasing demand for oil. China now is the second largest oil importer in the world after the United States and China is now the largest aggregate $\mathrm{CO}_{2}$ emitter in the world (Zhao 2010; IEA 2014).

On the other hand, the relatively low motorization rate and underdeveloped transport infrastructure means that cities in emerging economies like China have more scope to be flexible in adapting to environmental and climate challenges. For instance, China can choose to invest now in cleaner vehicle technologies, for example electric vehicles and hybrids or bus rapid transit systems (Ni, Bai, and Sperling 2008). There is potential for using different urban forms and layouts; for example, controlling sprawl by designing urban development around fast public transport, connecting high-density nodes of residences, places of employment, and commercial and leisure activities (Ng and Schipper 2005; Banister and Hickman 2009; Hickman, Ashiru and Banister 2009b).

In order to promote cities to move to a low-carbon transport system, it is of pressing importance to understand what the existing urban transport system looks like and how it functions in practice. Economically and socially vibrant urban areas cannot exist without a system for moving people, goods, and services. Transportation in urban areas is highly 
complex because of the modes involved, the multitude of origins and destinations, and the amount and variety of traffic. Car dependency, traffic congestion, long commuters, sprawl, and associated air and noise pollution characterize many contemporary cities, which challenges those cities to be sustainable. The health of cities, and their ability to generate income and wealth income and wealth for their inhabitants, is improved if the transportation system is efficient, and if its construction and operation considers its impacts on citizens, land use, the environment and economic development. How the transportation system in a city performs depends both on public investment and policy, and on millions of decisions made daily by consumer-travelers about whether, where, how and when to travel. Understanding how people make travel choices is key to understanding urban transportation problems and potential solutions.

This study aims to understand the existing urban passenger transport system in Hong and Shenzhen from the perspective of human travel behavior, examining closely what factors influence individual travel behavior in the two cities. The research is based on comparisons drawn from household and individual travel surveys conducted in the two cities. The urban transport system is the bone of the city supporting both passengers and freight mobility. This research focuses on the passenger transport system. It does not examine every element of the urban passenger transport system, but focuses on those aspects covered by the survey.

Data from travel surveys provide essential information for traffic planners, public transport providers, infrastructure authorities, and transport scientists (Nitsche, et al 2014). The analysis of individual travel behavior can improve the understanding of $\mathrm{CO}_{2}$ emissions caused by passenger transportation by identifying upstream socio-economic factors, relating behavior to different government policies, and enabling a better assessment of the potential social impact of measures introduced to limit greenhouse gases due to transport (Nicolas and David 2009). 
Hong Kong and Shenzhen are ideal cases to understand sustainable transport systems in both developed and emerging economies. Shenzhen is in one of China's most successful Special Economic Zones (SEZs) and has been one of the fastest-growing cities in the world, situated just north of Hong Kong. Shenzhen's socioeconomic development and material living standards are among China's best, and Shenzhen has made significant efforts to promote a low-carbon transport system. It is the seventh city in mainland China to build a subway system and is one of five pilot cities for promoting hybrid and battery vehicles through a governmental subsidy program.

Hong Kong is one of the most densely populated territories in the world, with a land mass of $1,104 \mathrm{~km}^{2}$ and a population of seven million people. Hong Kong has succeeded in transforming itself from a pre-industrial settlement to a dynamic global urban center and one of the world's leading international financial centers. It has a highly developed and sophisticated transport network, encompassing both public and private transport. Over $90 \%$ of daily journeys are on public transport, one of the highest rates in the world. However, according to one study, Hong Kong still has the second highest carbon footprint per capita in the world, due to the city's high consumption patterns and large volume of imports (Hertwich and Peters 2009). Energy end-use increased by 29.2\% from 1990 to 2007, during which time energy use by the transport sector increased by $37.1 \%$ (Chung Kam and Ip, 2011). It therefore is important to understand how Hong Kong's transport system can be improved, and to consider aggressive strategies for shifting to alternative energy vehicles to meet the above carbon reduction target. Real gains can be made through the cross-fertilization of experience and the tailoring of policy interventions to specific city contexts. The experience of Hong Kong can provide insights helpful for creating future sustainable cities in emerging economies, such as Shenzhen, and, increasingly, vice versa.

Household travel surveys provide information about individual travel behaviour (e.g., 
travel modes, distance, time, and cost). They have been conducted in many large cities worldwide (e.g., London, Seattle, and Washington D.C.) and even at the national level in the United States, the United Kingdom, and New Zealand. The data have been used for planning purposes and for academic research on transport management, energy consumption and carbon emissions (Lee, Hickman, Washington, 2007; Donegan, Adamson, Donegan, 2007; Stopher and Greaves, 2007; Liu and Shen, 2011; Collia, Sharp, and Giesbrecht, 2003; Mohammadian, Javanmardi, and Zhang, 2010). Hong Kong's Transport Department conducts a Travel Characteristics Survey periodically (in 2002 and 2011) that asks basic information about travel behavior and individual and household characteristics (www.td.gov.hk). In mainland China, however, little historical data on travel behaviour and travel distance are available except for a few small, special-purpose surveys such as a travel survey conducted in Beijing for the Olympic Games and a travel survey conducted in Shanghai for the World Expo (Beijing Transport Commission 2009). The Beijing Institute of City Planning conducts a large-scale household travel surveys in Beijing every five years but the data is not publicly available (Zhou et al 2014). Understanding the behavior of different types of consumers will be essential for designing appropriate policies to reduce energy consumption and carbon emissions.

The rest of the paper is organized as follows. The survey data sets used for analysis are described in Section 2. Analysis of behavioral factors affecting transportation choices is conducted in Section 3, include assessments of travel modes, frequency and duration of trips, and purposes of trips; growth in the vehicle population; promotion of electric vehicles, use of the public transport system, and use of non-motorized transport. A final section concludes.

\section{Data Sources}

The data used in this study come from three separate surveys conducted in Shenzhen 
and Hong Kong at different times. The first survey was conducted by the authors in Shenzhen, China, in the fall of 2014. The survey was administered through face-to-face interviews of Shenzhen residents aged 15 years or older conducted in all ten of Shenzhen's urban districts, with the assistance of enumerators from a local survey research company. The authors directed the training of enumerators and supervised and monitored the field research. Surveys were conducted of 1015 individuals, with great care taken to ensure that the sample accurately reflected the population distribution (as measured by the 2010 census) with respect to age, education, gender, and district location. Respondents were recruited through two methods: snowball sampling using contact lists of residents kept by the local survey company, and random interviews of individuals approached in key neighborhood locations, such as markets, entrances to apartment complexes, etc.

The second and third surveys were conducted in Hong Kong in 2002 and 2011 by the Hong Kong Transport Department. The samples in both Hong Kong surveys are randomly selected households from randomly selected neighborhoods. ${ }^{1}$ All members aged 2 or above in selected households are interviewed.

The questionnaires in the three surveys consist of two parts: 1) a general survey, including questions on basic socio-economic characteristics, vehicle ownership, normal usage of different travel modes, and so on; and 2) a 24-hour trip-diary, which records chronologically the travel information of all the trips made by the respondents during the previous day. The travel information includes the purpose of each trip, the transport modes and time spent on each leg of each trip, the starting and stopping address for each leg of each trip, and other information such as fares and fees, the number of passengers, parking location, etc.

The Hong Kong data has two limitations. First, in 2011 the trips of respondents who did

\footnotetext{
${ }^{1}$ The neighborhoods are quarters or area segments in the Frame of Quarters maintained by the Census and Statistics Department.
} 
not use motorized transport or bicycles during the day were not recorded (even if they had walking trips). This presents us from comparing some results for Hong Kong in 2011 with the other two surveys. Secondly, the travel distance of each leg is not recorded in either Hong Kong survey, which prevents us from comparing travel distances in Hong Kong and Shenzhen.

Ultimately, we have 1015 individual samples from 1015 households in Shenzhen in 2014, 92154 individual samples from 29981 households in Hong Kong in 2002, and 101385 individual samples from 35401 households in Hong Kong in 2011. The age, gender, education and district distributions ${ }^{2}$ of the samples of the three samples are mostly identical to those found in the 2010 population census in Shenzhen, and the 2001 and 2011 population censuses in Hong Kong.

To measure transportation behavior accurately, we examine trips (or trip chains) which may consist of multiple legs. Fig. 1 illustrates the concept of trip legs, which are defined as segments of a trip separated by transport mode changes or intervening activities with a short dwell time (cf. McGuckin and Nakamoto, 2004).

\footnotetext{
${ }^{2}$ Due to space considerations, we do not report the detailed distributions in the paper. For those interested, please refer to Zhao et al. (2015) for the Shenzhen data, and the government reports for the Hong Kong data in both years, which are available from

http://www.td.gov.hk/en/publications and press releases/publications/free publications/index.html [last access on 20151230].
} 


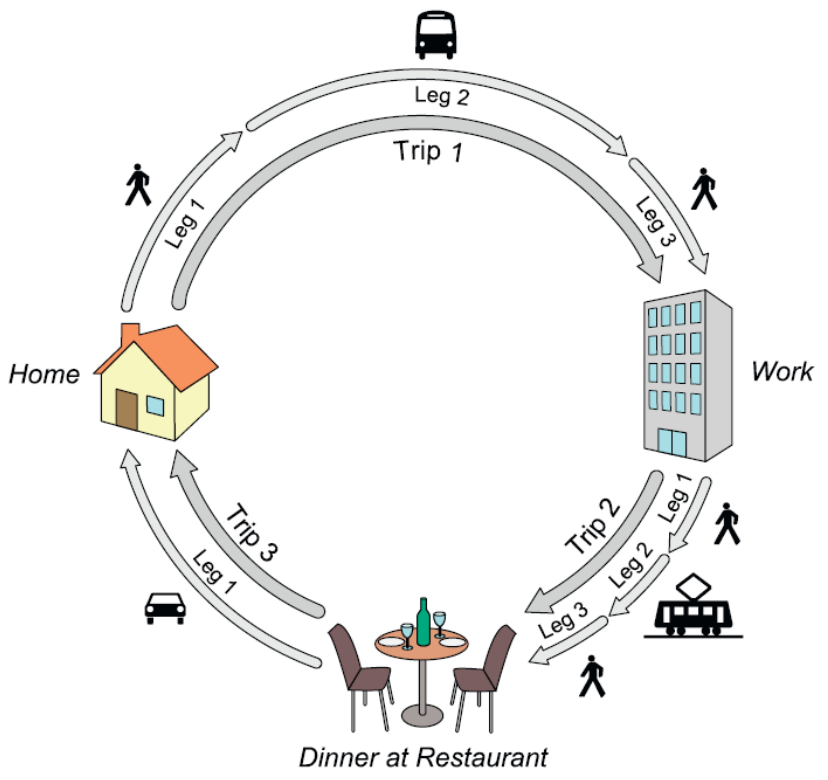

Figure 1. Illustration of an exemplary trip chain with trips and trip legs

(Nitsche et al 2014)

\section{Assessment of Urban Transport Systems}

Mobility is an outcome of personal choice as is the means of travel, such as the automobile, walking, cycling and the motorcycle. Travelers make decisions they think are in their best interest, and they have a lot of travel experience to help them with those choices. Travelers try to optimize their outcomes in the context of the benefits and costs that they personally incur.

Urban transport consists of a family of modes, which range from walking, bicycles, to buses, urban metro, and regional rail systems. ESCAP (2012) provides a definition of sustainable transportation system. The main objectives of a sustainable transportation system are to: (i) Reduce the travel demand, particularly by motorized modes by reducing the number of trips and trip lengths; (ii) Greater use of truly sustainable modes (i.e. walking and other non-motorized transport); (iii) Efficient use of existing systems and reducing the use of all resources - natural, physical and financial; (iv) Increasing energy efficiency and emission 
standards of motorized vehicles.

Cities with sustainable transport systems are characterized by high public transport mode shares, transit-oriented development aimed at reducing travel demand, restricting car usage and facilitating the use of non-motorized modes.

\subsection{Travel Modes, Trip Frequency and Duration, and Trip Purposes}

Travel mode. The choices that individuals make about travel mode is most consequential for energy use and carbon emissions. In Shenzhen, driving a car consumes nearly 10 times as much energy as taking public transportation and emits nearly 5 times as much $\mathrm{CO}_{2}$ (Zhao et al, 2015).

In Shenzhen non-motorized transport (walking and bicycling) accounts for $50 \%$ of all passenger trips, where trips are calculated by their main mode (that used for the longest leg measured by distance). Walking no more than 10 minutes is the dominant mode and the average distance is 516 meters, which suggests that short-distance trips are significant part of people's daily lives. Such a pattern is facilitated by sound job-housing balance in terms of urban planning. Buses and subways account for $20 \%$ and $7 \%$ of passenger trips and $54.7 \%$ of all motorized passenger trips which is close to the goal for public motorized passenger trips to reach $56 \%$ by the end of $2015 .{ }^{3}$ This share is substantially higher than that reported by Zhen (2013) for Shenzhen in 2010, suggesting that progress has been made encouraging individuals to use public transportation. The other motorized main travel modes are cars (or vans) and taxis, which account for $16 \%$ of all trips, and electric 2 -wheel vehicles, which account for $6 \%$ of trips.

\footnotetext{
${ }^{3}$ According to governmental statistics (SBS, 2015), there were approximately 136,000 tourists daily in Shenzhen in 2014, who are supposed to use franchised buses and public transports as major modes for travel, and our result on share of public transport could be underestimated.

${ }^{4}$ It is stated by local government in Shenzhen's $12^{\text {th }}$ Five-Year Plan (FYP) on social and economic development, available from http://zwgk.gd.gov.cn/007543382/201111/t20111123 293130.html [last access on 20150628].
} 


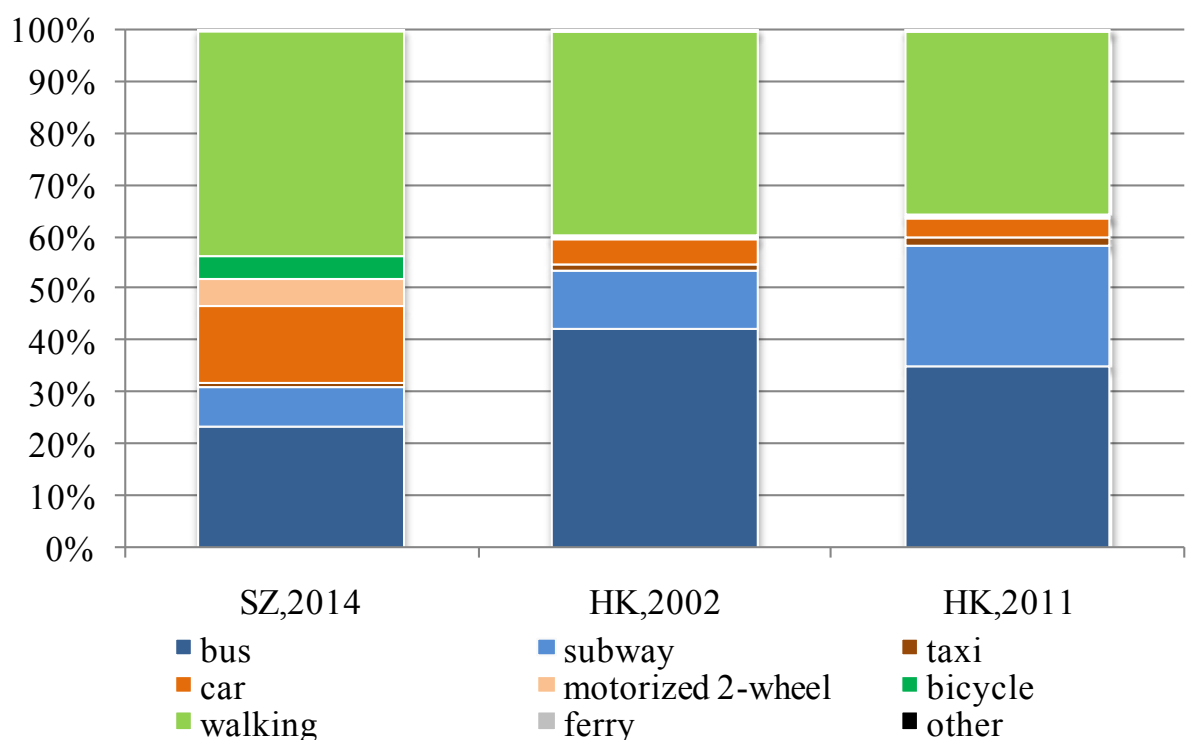

Notes: Shares are for all legs of all trips.

Figure 2: Travel Modes in Hong Kong and Shenzhen

In Figure 2, we compare the frequency of using different travel modes in Shenzhen and Hong Kong. For comparison purposes, we calculate the shares of all trip legs using each mode. ${ }^{5}$ Figure 2 makes evident that compared to Shenzhen, Hong Kong has achieved much greater success in encouraging citizens to use public transportation and to not drive cars. In Hong Kong, buses and subway accounted for $41.9 \%$ and $11.3 \%$ of trip legs in 2002 and $35.0 \%$ and $22.3 \%$ in 2011 , compared to $23.4 \%$ and $7.5 \%$ in Shenzhen. Thus, in Hong Kong the share of subway trips nearly doubled in 9 years, while that of buses declined somewhat. In Hong Kong, the share of trip legs using cars and taxis was less than $7 \%$ in both 2002 and 2011 (and declining slightly over time), which is less than half the share in Shenzhen even though incomes are considerably higher in Hong Kong. We discuss the reasons for these disparities in more detail in sections 3.2 and 3.4 below.

\footnotetext{
${ }^{5}$ The shares in this figure will differ slightly from the shares of trips defined by main mode. Unfortunately, the Hong Kong data does not include information on the distance of each leg, so we cannot define a main mode for each trip.
} 
Travel frequency and duration. In Shenzhen in 2014, people took 2.97 trips per day on average, compared to 2.72 trips per day in Hong Kong in $2002{ }^{6}$ These numbers are much smaller than in the U.S., where the average trips per day is 3.79 (DOT, 2011). Each day, those living in Shenzhen spent 84 minutes per day traveling, 9 minutes more than the respondents in Hong Kong in 2002, and 20 minutes more than Seoul citizens (Choi, et al., 2014). If we restrict attention to those who used motorized transport for at least one trip leg, the average daily travel time was 104 minutes in Shenzhen in 2014, 93 minutes in Hong Kong in 2002, and 88 minutes in Hong Kong in 2011. Thus, Hong Kong experienced improvement in transport efficiency. Overall, time spent per trip seems comparable in the two cities, with slightly more trips in Shenzhen. Thus, despite differences in population density and incomes, differences in overall demand for trip number and duration are unlikely to explain differences in transportation patterns in the two cities.

Trip purposes. Next, we compare the purposes of trips in Shenzhen and Hong Kong (Figure 3). Comparing Shenzhen in 2014 and Hong Kong in 2002, in both cities over $60 \%$ of all trips are to go to work or return home. ${ }^{8}$ However, among non-home trips, the share of work trips is noticeably higher in Shenzhen than Hong Kong. This is consistent with the findings that higher incomes and older age are associated with more non-work trips (Hu et al., 2013). Interestingly, when looking separately at motorized trips and walking trips, we find that the share of non-work trips is much greater for walking trips than for motorized trips in Hong Kong, but only slightly greater in Shenzhen. This suggests that Hong Kong's urban structure (population density, nearby availability of shops, restaurants, and services) enables a

\footnotetext{
${ }^{6}$ In the Shenzhen sample, the 996 respondents who reported trips made 2954 trips in the previous day. The rest 19 samples were not in SZ or did not go out on the surveyed trip-day.

${ }^{7}$ The data for Hong Kong in 2011 contain only travel information for samples that used motorized transport or bicycles at least once. Thus, we are unable to calculate mean duration of all trips in Hong Kong in 2002.

${ }^{8}$ The ratio of non-work trips to work trips is much smaller in Shenzhen and Hong Kong than in the US, where work-related activities accounted for $22 \%$ of trips and social and other recreational activities accounted for more than $30 \%$ of trips according to the 1995 Nationwide Personal Transportation Survey by the Federal Highway Administration, available from https:/www.fhwa.dot.gov/ohim/onh00/onh2p9.htm [last access on 20150720]. Americans also travel much further each day $(58.1 \mathrm{~km}$ on average) than residents of Shenzhen $(19.4 \mathrm{~km})$ (DOT, 2011).
} 
greater share of individuals to meet non-work trip needs in locations that are within walking distance.

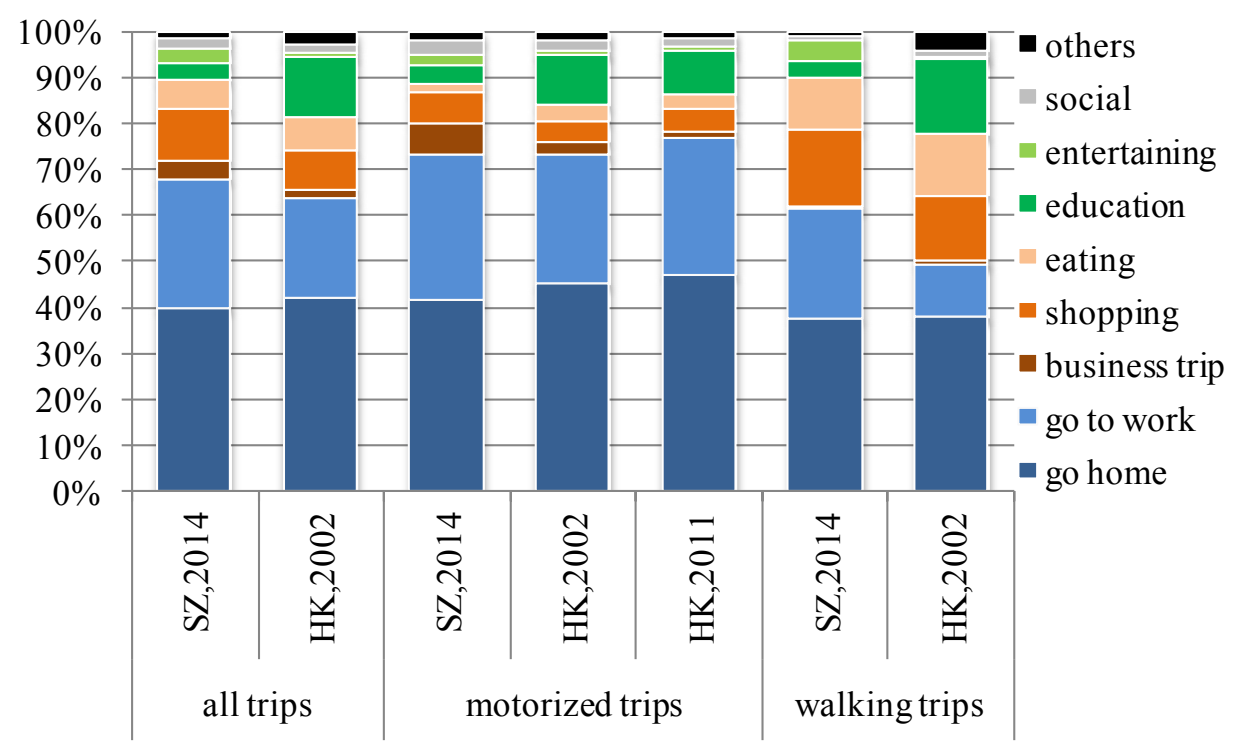

Figure 3. Trip purposes, by transportation mode

\subsection{Vehicle Population}

Increased car use in urban environments leads to multiple negative outcomes, including traffic jams, air pollution, and increased $\mathrm{CO}_{2}$ emissions. Many cities in China have been experiencing serious air pollution, and emissions from car use are are a major contributor. Reducing car ownership and especially car use is a key indicator of a sustainable urban transport system. Figures $\mathrm{xx}$ and $\mathrm{xx}$ plot the total private car population and the ownership of private cars per 1000 people in Hong Kong and Shenzhen over time. The private car population in Shenzhen increased much later than in Hong Kong but has increased much more rapidly in recent years, while Hong Kong's private car population has increased very slowly. 


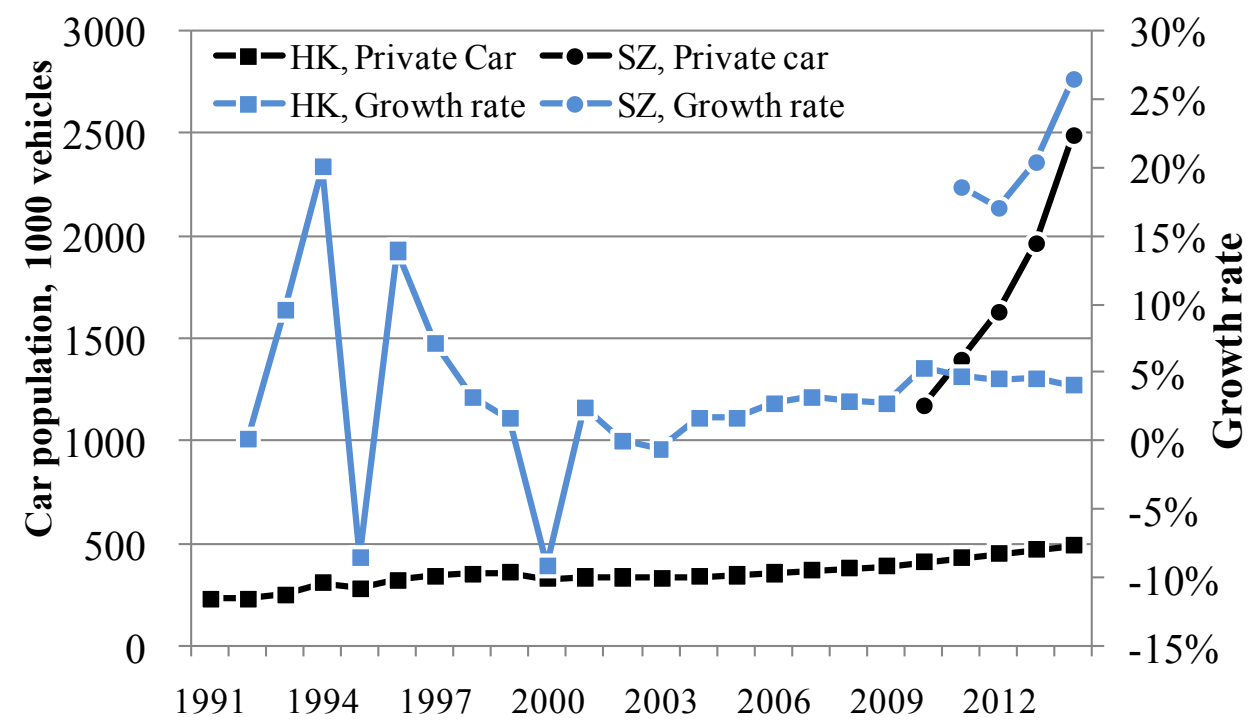

Data sources: Shenzhen Statistics Yearbook 2010-2014; HK...

Figure Private Car Population in Shenzhen and Hong Kong

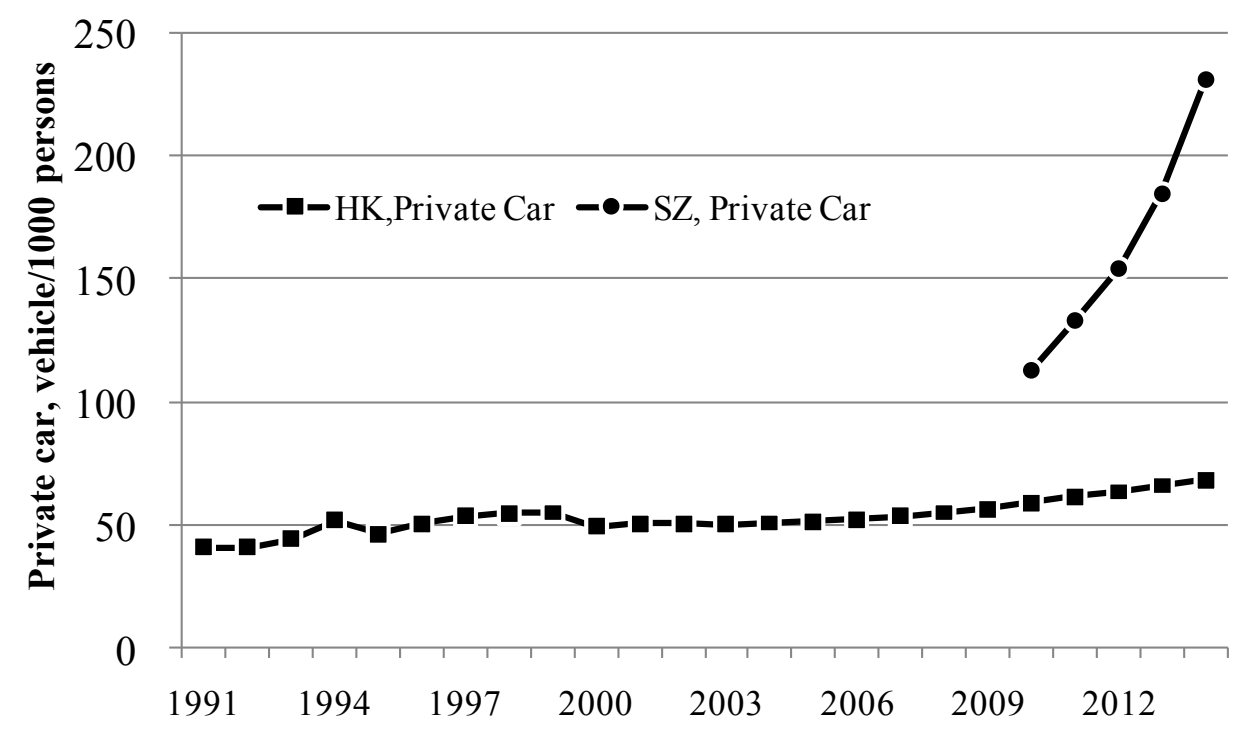

Figure : private cars per 1000 persons in both cities.

Our survey results also reveal the same rapid increase in private car use in Shenzhen, especially after 2009 when the purchase tax reduction policy was introduced ${ }^{9}$. As seen in

\footnotetext{
${ }^{9}$ The purchase tax, also called first registration tax, for private cars with cylinder size no bigger than 1.6L was $50 \%$ off between 2009 and 2010, 25\% off between 2010 and 2011, and abolished in end of 2011.
} 
Figure $\mathrm{xx}$, annual purchases by sample respondents in the years after 2009 are twice as great as in years before 2009. In total, $75 \%$ of cars owned in 2014 were purchased after $2009,50 \%$ of which are private cars with cylinders smaller than 1.6L. The number of newly-purchased cars dropped in 2011 due to the suspension of the tax policy, and continued to increase afterwards with rising incomes.

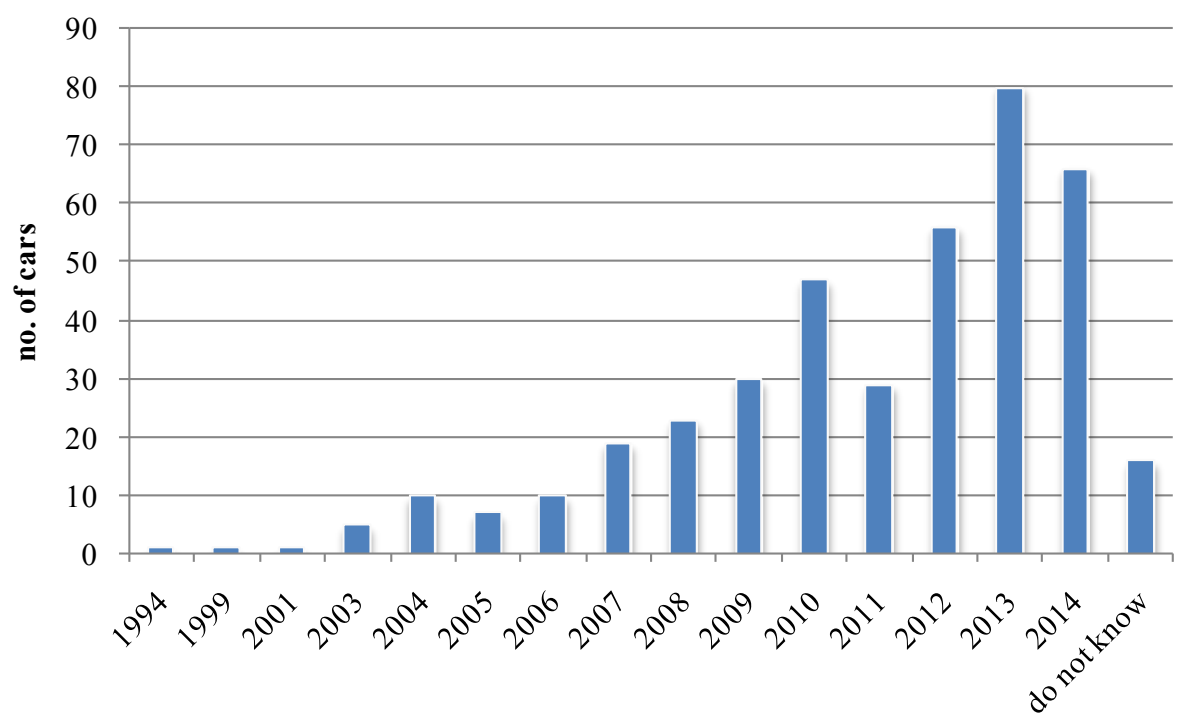

Fig. Xx. The purchase year of surveyed private cars

$36.4 \%$ of households interviewed owned at least one car in Shenzhen, while $14.4 \%$ of households in Hong Kong had private cars available for use, among which $11.4 \%$ had more than 1 car based on Hong Kong's 2011 survey. In Hong Kong in 2011, 95\% of all households with available vehicles reported that they used their vehicles at least once during the past seven days. The annual average distance driven by private cars was $11,400 \mathrm{~km}$ and by motorcycles was $11,600 \mathrm{~km}$. These compare to $16,000 \mathrm{~km}$ and $11,800 \mathrm{~km}$ respectively in 2002, which reflects a considerable reduction in the annual average distance travelled by private cars. Regarding the purposes for private car trips in Hong Kong in 2011, 63\% were used mainly for recreational and social activities, and commuting to and from work. In 
contrast, in Shenzhen $68 \%$ of trips were solely for commuting to and from work and social and entertainment activities accounted for only $6 \%$.

The close relationship between vehicle ownership and household income is seen in the survey results. Both the Hong Kong and Shenzhen surveys show that vehicle ownership is positively associated with household income levels, especially at the highest levels of income (Figure $\mathrm{x}$ ). In Hong Kong, the association becomes strong at a higher income level, e.g., HK\$ 60,000 to 80,000 . This may be attributed to the much higher cost of buying and maintaining a car in Hong Kong, where there are extremely high tariffs on imported cars and large annual registration fees. We also find that the households with higher income in Shenzhen tend to buy low fuel economy cars, mostly because those vehicles have bigger engine size and are luxury cars.

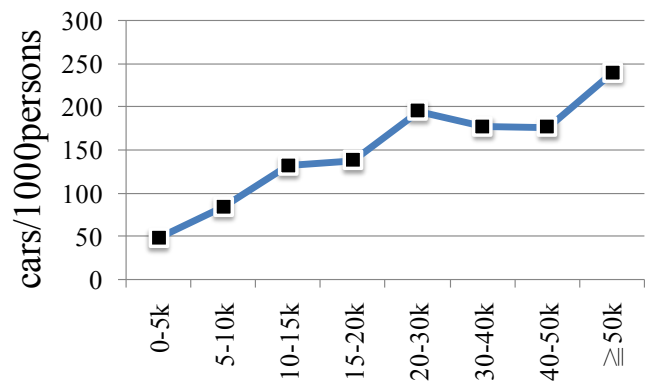

a) SZ, 2014

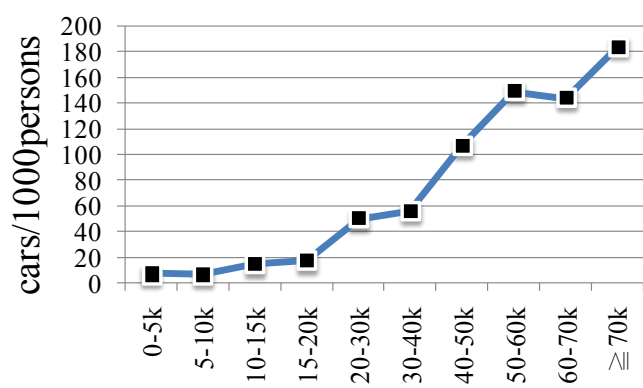

b) HK, 2002

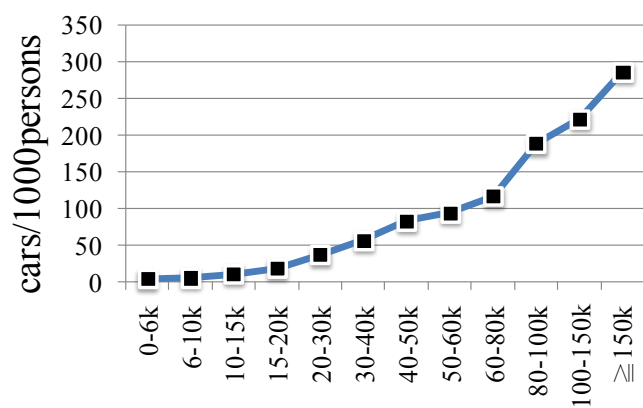

c) HK, 2014

Figure : Car ownership of household groups with different monthly income level (in units of 
local currency at current prices) in both cities.

The private car population in Shenzhen will continue to increase in the future along with income increases and relatively low existing vehicle ownership. $42 \%$ of respondents plan to purchase a private car in the next 5 years, and of these future car buyers $83 \%$ of them do not have a car now. Without more aggressive government policies, vehicle fuel consumption will continue to increase rapidly not only because of a higher vehicle population but also average fuel economy will worsen due to the desirability of purchasing larger vehicles (e.g., SUVs).

In order to reduce the environmental impacts and traffic jams caused by a rising vehicle population, the Shenzhen government established a car quota policy in 2014 to restrict the number of new cars to 100,000 units every year for the following five years. ${ }^{10}$. The policy allocates the quota in the following manner: $20 \%$ for electric cars by lottery, $40 \%$ for conventional cars by lottery, and the remaining $40 \%$ for conventional cars by auction. As a result, the car population will increase at a lower speed if the government can successfully limit citizens from driving vehicles registered in other cities, which has been a problem in other cities with strict controls, like Beijing. We asked respondents if they support a quota policy to restrict the vehicle population, and $20 \%$ of them support it but these are mostly not potential car buyers. Shenzhen can also learn from Hong Kong's experience to increase the cost of purchasing vehicles and at the same time to provide high quality public transport options.

Both the Shenzhen and Hong Kong surveys ask respondents why they made the decision to buy a car. The results are quite similar (see Figure ). Top four reasons in Hong Kong include saving time, need for work, family use, no need to transfer. As for Shenzhen,

\footnotetext{
${ }^{10}$ Among the 100,000 new cars, $20 \%$ are for electric cars by lottery, $40 \%$ are for conventional cars by lottery, and the rest $40 \%$ are for conventional cars by auction.
} 
the top three reasons are convenience, need for work, and family need.

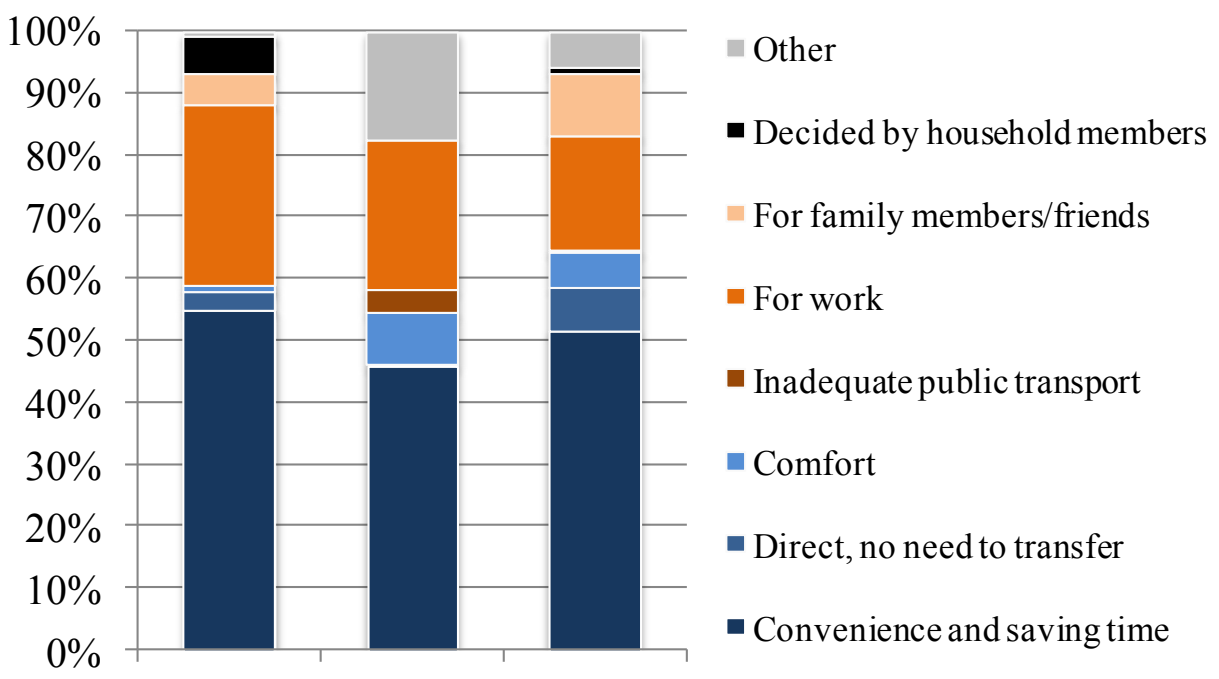

SZ, 2014 HK, 2002 HK, 2011

Figure : Why did you buy the car?

It should be noted that the Shenzhen government now forbids the use of gas motorcycles in major urban areas and roads due to safety concerns, with restrictions placed on electric bicycles on some roads as well. ${ }^{11}$ The ownership of gasoline-fueled motorcycles thus is probably underestimated because people do not want to report their use. The selfreported ownership of motorcycles and electric bikes per 1000 persons are 6 and 60, respectively. $7 \%$ of the respondents plan to purchase electric bikes in the future. Electric bikes can be a sustainable transport mode if the Chinese electricity structure can be shifted to use more renewable energy sources.

\subsection{Electric Vehicles}

Electric vehicles (EVs) have been claimed to provide a key pathway towards

\footnotetext{
${ }^{11}$ In general, majority of the areas in Shenzhen applies the ban. Details of the areas for motorcycles are available from http://jt.sz.bendibao.com/news/2015415/685113.htm [last access on 20150627], and the details for electric two-wheels are available from http://jt.sz.bendibao.com/news/2015415/685131.htm [last access on 20150627].
} 
sustainable urban transport. In China, in particular, EV deployment is seen as a solution not only for mitigating rising oil dependence but also for improving air quality faced by many Chinese cities and reducing carbon emissions if electricity can be generated with extensive use of renewable energy sources (Ou et al., 2010; Huo et al., 2013). Both the Shenzhen and Hong Kong governmentsj, as well as business partners (e.g., automotive manufacturers, electricity suppliers), made great efforts to promote the deployment of EVs. Shenzhen is one of 6 pilot cities that joined China's national pilot program to promote both public procurement and private purchase of EVs. Private buyers in Shenzhen can receive a subsidy of up to RMB 60,000 from the national and Shenzhen municipal governments (Hao, et al., 2014). BYD Ltd, the largest local EV manufacturer in Shenzhen, is the most innovative and independent national auto brand and leads EV manufacturing development in China. Shenzhen is regarded as having achieved greater success than other cities in China in promoting EV use (Li et al., 2015).

The Hong Kong government established the Steering Committee on the Promotion of EVs in April 2009, which is headed by the Financial Secretary and includes members from property development, car park operations, power supply sectors, technology institutions, green groups and academia. The Hong Kong government also provides subsidies to bus companies or goods vehicle owners. For example, a HK\$300 million Pilot Green Transport Fund (PGTF) was set up in March 2011 to subsidize public transport operators and goods vehicle owners to try out green innovative transport technologies including EVs. It does not provide subsidies to private buyers of EVs but does offer tax incentives; the first registration tax has been waived for EVs since 1994 and has been extended until March 2017.

Even though both governments have made significant efforts to promote EVs as described above, the development of electric vehicles has been slow in both cities. Shenzhen has been more successful than Hong Kong. As shown in Table 1, the development of EVs in 
both cities is still at an early stage. The share of EVs in the total vehicle population is less than $0.5 \%$ in both cities but is higher in Shenzhen $(0.37 \%)$ than in Hong Kong $(0.26 \%)$. There are many more buses, taxis and government cars that are EVs in Shenzhen than in Hong Kong. Considering that these sectors are either directly invested or intensively regulated by the government in both cities, it indicates a much stronger role of local government in Shenzhen than in Hong Kong in promoting EVs.

Table 1: EV population in Shenzhen and Hong Kong

\begin{tabular}{|c|c|c|c|c|c|}
\hline \multirow[b]{2}{*}{ Item } & \multirow[b]{2}{*}{ Unit } & \multicolumn{2}{|l|}{ Status quo } & \multicolumn{2}{|l|}{ Future Plan } \\
\hline & & $\begin{array}{l}\text { Shenzhen } \\
\text { by } 11 / 2014\end{array}$ & \begin{tabular}{ll}
\multicolumn{2}{c}{ Hong } \\
Kong & \\
& by $02 / 2015$
\end{tabular} & $\begin{array}{l}\text { Shenzhen } \\
\text { no specific } \\
\text { year }\end{array}$ & $\begin{array}{l}\text { Hong Kong } \\
\text { by } 2020\end{array}$ \\
\hline EV Total & Aars & 9392 & 1804 & - & - \\
\hline BEV bus & Aars & 1279 & \multirow{2}{*}{12} & \multirow{2}{*}{$70 \%$ of new } & \multirow{2}{*}{$15 \%$ of tota } \\
\hline HEV bus & cars & 1771 & & & \\
\hline BEV taxi & cars & 850 & 48 & $70 \%$ of new & - \\
\hline EV passenger car & cars & 5430 & \multirow{2}{*}{1559} & encouraged & \multirow{2}{*}{$30 \%$ of total } \\
\hline -government car & cars & 520 & & $70 \%$ of new & \\
\hline EV motorcycle & cars & N.A. & 126 & - & - \\
\hline EV good/special & cars & 62 & 59 & $\begin{array}{l}30 \% \sim 50 \% \\
\text { of new }\end{array}$ & $30 \%$ of total \\
\hline Share of EVs in total & $\%$ & $0.37 \%$ & $0.26 \%$ & - & - \\
\hline
\end{tabular}

Data source: EPD, 2015. Shenzhen Municipal Government (SZMG), 2015. Development plan on newenergy vehicles in Shenzhen (in Chinese), available from: http://auto.huanqiu.com/roll/2015-03/5955932.html [last access on 20151225]. Hong Kong Environment Bureau (HKEB), 2015. Hong Kong Climate Change Report 2015. Available from: http://www.enb.gov.hk/sites/default/files/pdf/ClimateChangeEng.pdf [last access on 20151229].

The percentage of EVs in total cars surveyed in both Hong Kong and Shenzhen are higher than those in Table 1, which may due to the sample selection. In the Hong Kong 2011 survey, we found 11 battery EVs and 11 hybrid electric vehicles (HEVs) among 1224 surveyed respondents who have vehicles, accounting for $1.79 \%$. In Shenzhen, there were only 3 battery EVs and 3 HEVs out of 412 cars, accounting for $1.46 \%$ of total cars. The expectations of governments in both cities continues to be higher than the real actions of private buyers. According to the statistics of the car quota policy in Shenzhen in 2015, 20,000 
lottery quotas were assigned to EVs in Shenzhen while only 2146 were actually used ${ }^{12}$. Both governments have established ambitious future targets but defined differently. The Shenzhen government has set up a goal proportional to annual incremental vehicles, while the Hong Kong government has a goal based on the total vehicle population. Tremendous efforts are required to persuade vehicle owners to replace their gasoline cars with EVs.

In order to understand what are barriers causing slow development of EVs from the perspective of consumers, we analyzed the reasons that survey respondents claimed prevented them from buying an EV (see Figure ). Interestingly, we notice that the main reasons cited by potential car buyers in the two cities are divergent. We categorized the long list of reasons into four major types--technology, infrastructure, knowledge, and pricing. We find that citizens in Shenzhen choose not to buy an EV mainly due to reasons related to technology (mileage, safety, etc.) and pricing issues, while Hong Kong car buyers mainly cite infrastructure and knowledge (EV experience and awareness of EV models) issues.

Consequently, in order to persuade citizens to purchase an EV, more investment in EV technology and subsidies might be promising solutions in Shenzhen, while more investment in infrastructure and advertisement might be better alternatives for Hong Kong. Interestingly, when Shenzhen respondents are asked why they didn't buy EVs in previous years rather than about future purchase plans, a much larger share reports concerns about infrastructure and knowledge, a pattern more similar to Hong Kong prospective buyers. This suggests that the Shenzhen government has made clear progress investing in infrastructure and providing information about EVs.

\footnotetext{
${ }^{12}$ Data source: http://sz.southen.com/content/2015-08/10/content 130313480.htm [last access on 20151227].
} 


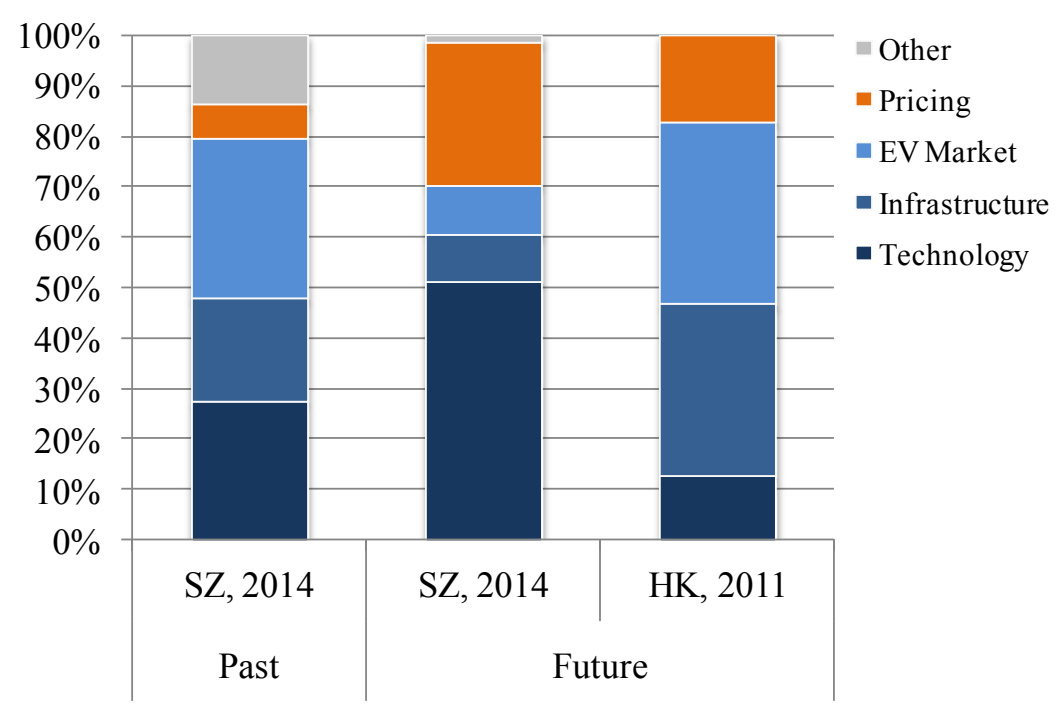

Figure : Why won't respondents buy an EV?

\subsection{Public Transport}

Public transport plays a vital role in providing mobility and access. It is the most cost-efficient and environmentally friendly mode of transporting large numbers of people. Hong Kong has a comprehensive public transport system comprising railway, franchised buses, public light buses, taxis, ferries, trams, and non-franchised buses. These public transport services are operated by the private sector or public corporations without direct government subsidy. As an emerging city, Shenzhen is still developing its public transport system. Subway service began in 2004, and has been developing rapidly. By 2015, it reached $177 \mathrm{~km}$ in total length (see Table $\mathrm{x}$ ). The length of operated subway lines in Hong Kong reached $218 \mathrm{~km}$ by 2014, which is longer than that of Shenzhen. In terms of per capita length, the gap is even greater--1.6 cm/person for Shenzhen compared to $3.0 \mathrm{~cm} /$ person for Hong Kong. Subway length per constructed area is $198 \mathrm{~m} / \mathrm{km} 2$ for Shenzhen, which is less than $1 / 4$ of Hong Kong $(817 \mathrm{~m} / \mathrm{km} 2)$ in 2014. However, the Shenzhen government has an ambitious subway development plan to double the subway length by 2020 and quadruple the subway 
length by 2030 (Table X).

Table X: Length of subway in Hong Kong and Shenzhen, km.

\begin{tabular}{lll}
\hline & HK & SZ \\
\hline By 2002 & 128 & 0 \\
by 2014 & 218 & 177 \\
by 2020 & 271 & 354 \\
by 2030 & N.A. & 719 \\
\hline
\end{tabular}

Data source: MTR, 2015. The Network Extensions. Available from:

http://www.mtr.com.hk/en/corporate/projects/projects_new_index.html [last access on 20151230].

Urban Planning Land and Resource Commission of Shenzhen Municipality (UPSZ), 2012. Planning on rail transport development in Shenzhen (in Chinese). Available from:

http://www.szpl.gov.cn/xxgk/tzgg/csghgg/201211/t20121119_77581.htm [last access on 20151228].

As for public buses, the number of buses in Shenzhen is fewer than that in Hong Kong in terms of both total bus population and buses per capita, as shown in Figure XX.

However, the annual growth rate in Shenzhen is around $10 \%$ and considerably higher than in Hong Kong, which ranged between $0 \%$ and $5 \%$ and leveled off at around $1 \%$ over the past five years.

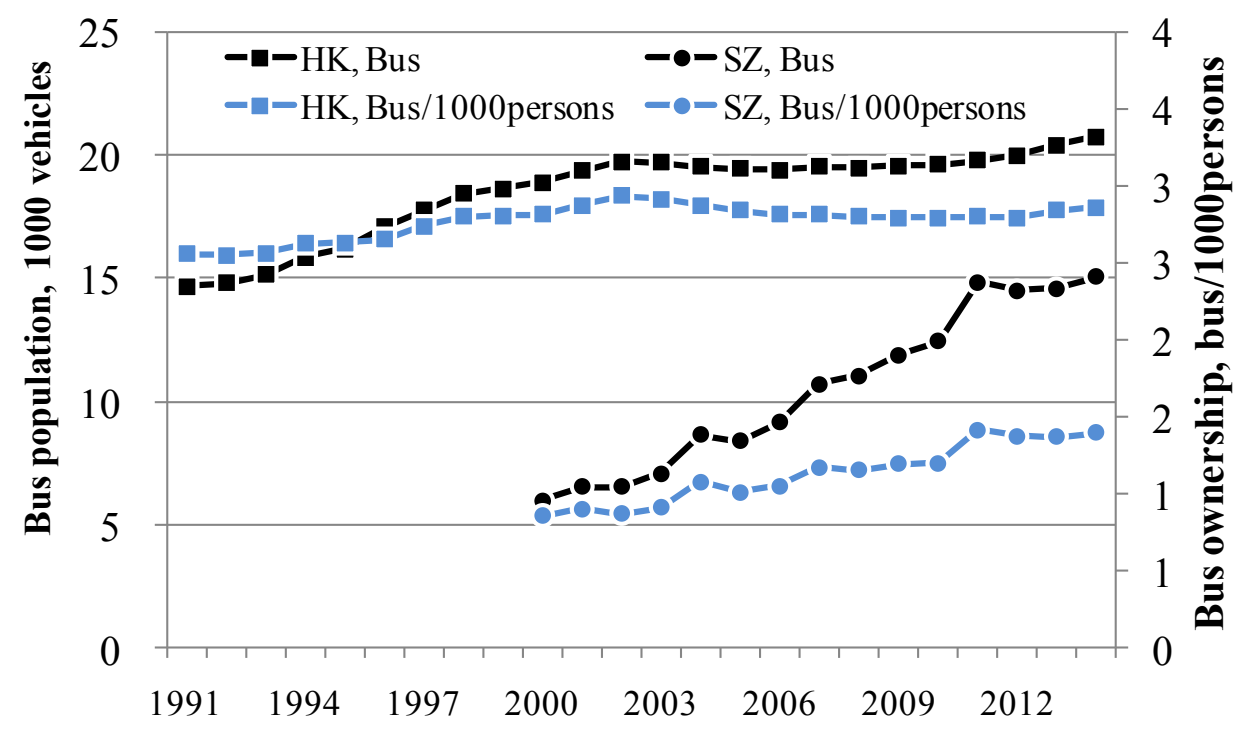

Figure XX: Bus fleet and ownership per 1000 persons in both cities. 
The gap in infrastructure supply is due to two major characteristics of the two cities. First, the development stages of the two cities are different. Shenzhen is a rapidly growing developing city while Hong Kong is relatively mature and developed. As a result, the demand, as well as available space, for new construction programs is higher in Shenzhen than in Hong Kong.

Second, the role that municipal governments can play is different due to different political systems. In Shenzhen, the government has a strong, even decisive, influence on public transport service providers, which are usually stated-owned enterprises. In Hong Kong, although the government is the major shareholder of the suppliers ${ }^{13}$, the role of the government is less overt. The enterprise law in Hong Kong stipulates that the program initiator is not allowed to vote on decisions related to the program. In addition, a very realistic political situation in Hong Kong is the fragmentation of political power. It is difficult for supporters to gain universal support, and thus budget approval, from competitors for government-initiated programs. These complexities explain the weak power of the government, even though it is the major share holder, in initiating environmentally oriented programs in local public transport service providers. As a result, government-initiated programs, especially environmental ones, will at best be superficially implemented for image considerations unless the program can be proven to be profitable.

While infrastructure supply can be led by government, the use of public transport relies upon individual decisions. We can take away a couple of key points from the trends displayed in Figure YY. First, as subway service supply increased significantly in Hong Kong during the past decade, the share of trips using the subway increased from $15.6 \%$ in 2002 to $26.4 \%$ in 2011 , which was offset somewhat by a decline in bus usage from $45.6 \%$ in 2002 to $35.2 \%$ in 2011 . Notably, the share of cars in the passenger trips did not change much

\footnotetext{
${ }^{13}$ For instance, Hong Kong municipal government holds $76.82 \%$ shares of MTR.
} 
over this period as seen in Figure xx. This suggests that the competition over long-distance trips is mainly between buses and subway, and that policies other than increasing service supply may be needed to encourage citizens to substitute car use with public transport use.

Second, the share of public transport users is considerably smaller in Shenzhen than in Hong Kong, due mainly to a smaller share of subway users in Shenzhen. The difference is in accordance with the earlier finding that the share of trip legs that use public transport is significantly higher in Hong Kong than in Shenzhen (Figure xx).

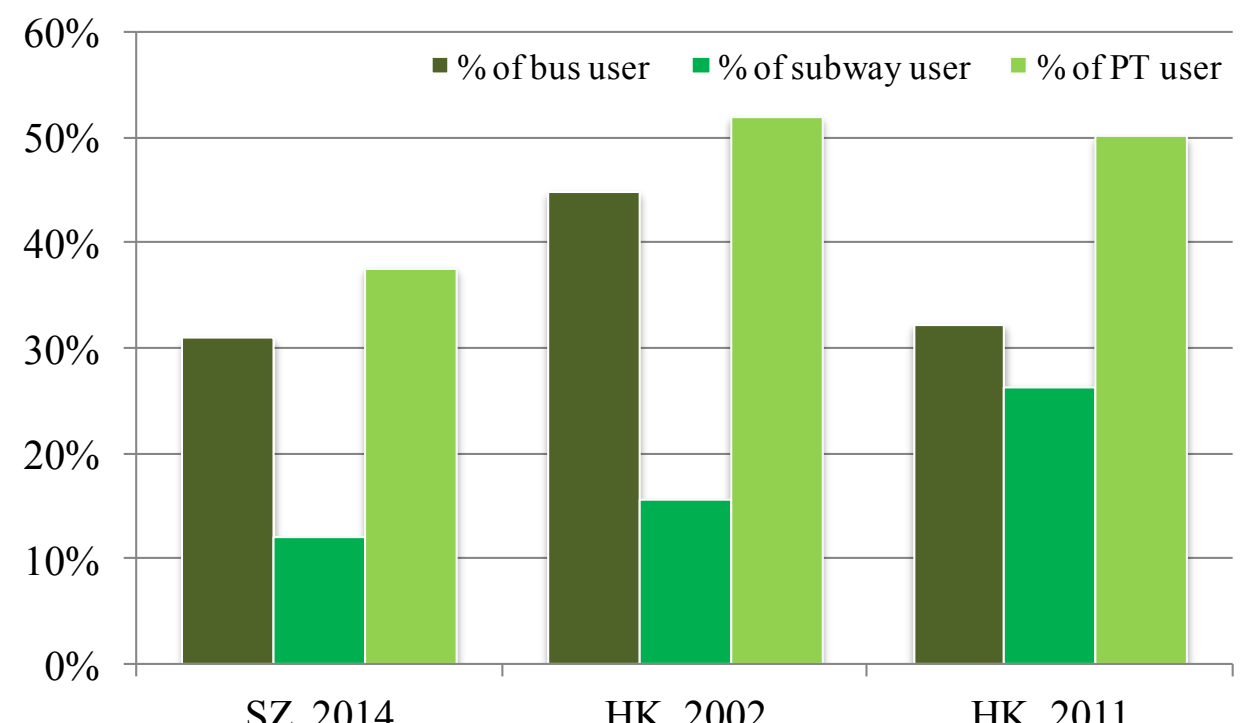

Figure YY: share of PT users among all respondents in both cities.

Hence, we investigate further into the reasons why Shenzhen respondents choose not to use public transport. As shown in Figure ZZ, having alternative transport modes (cars , two-wheels and walk) is the dominant reason. Service quality such as travel time and crowded vehicles account for $6 \%$ and $5 \%$, respectively. This might also help explain the higher share of public transport modes in Hong Kong. Besides the more intensive and higher quality of public transport service supply, there are also less motorized alternatives, such as 
cars and two-wheel vehicles, in Hong Kong compared to Shenzhen.

However, the results become contradictory when we ask respondents in Shenzhen about which policies they think will increase their use of bus and subway. As shown in Figure AA, the most supported policies by both public transport users and non-users are about the service quality, including comfort, reliable timing, less wait, convenient transit, and so on. Policies related to the major reasons cited by non-users in Figure ZZ, such as reducing taxi-service (the car alternatives), are not equally supported. This indicates not only the tremendous room of educating the public, but also the difficulty in persuading public transport non-users to become users.

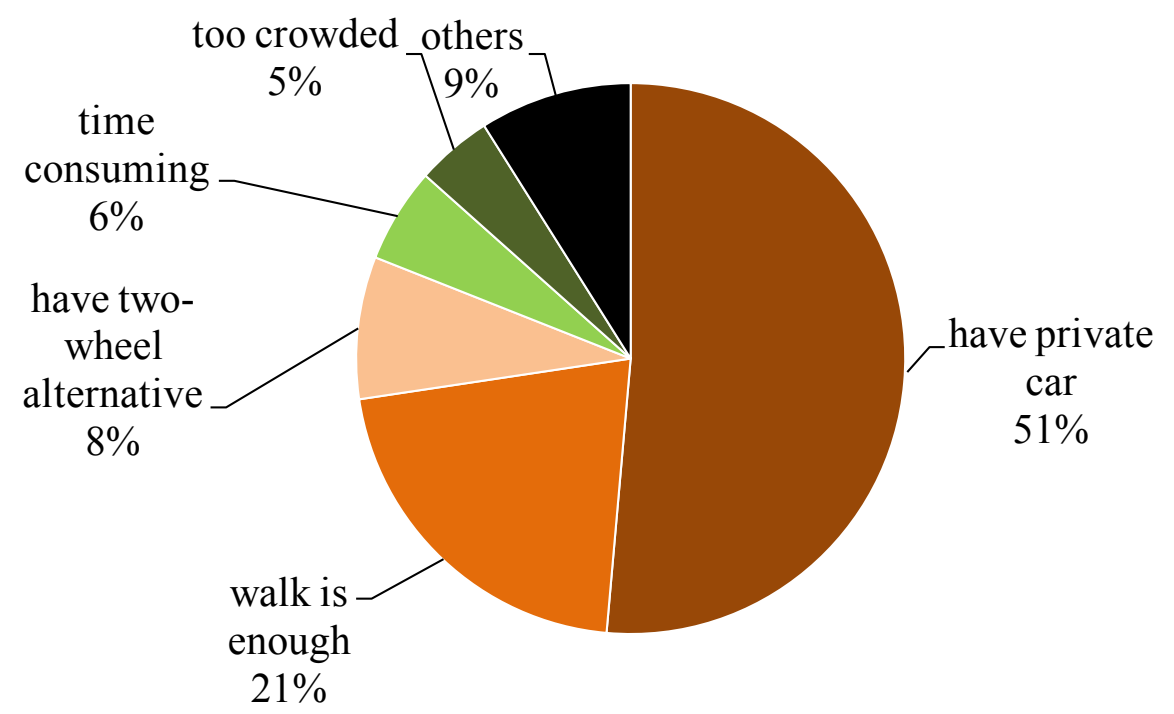

Figure ZZ: Why do not you use the public transport in the past 1 month in Shenzhen? 


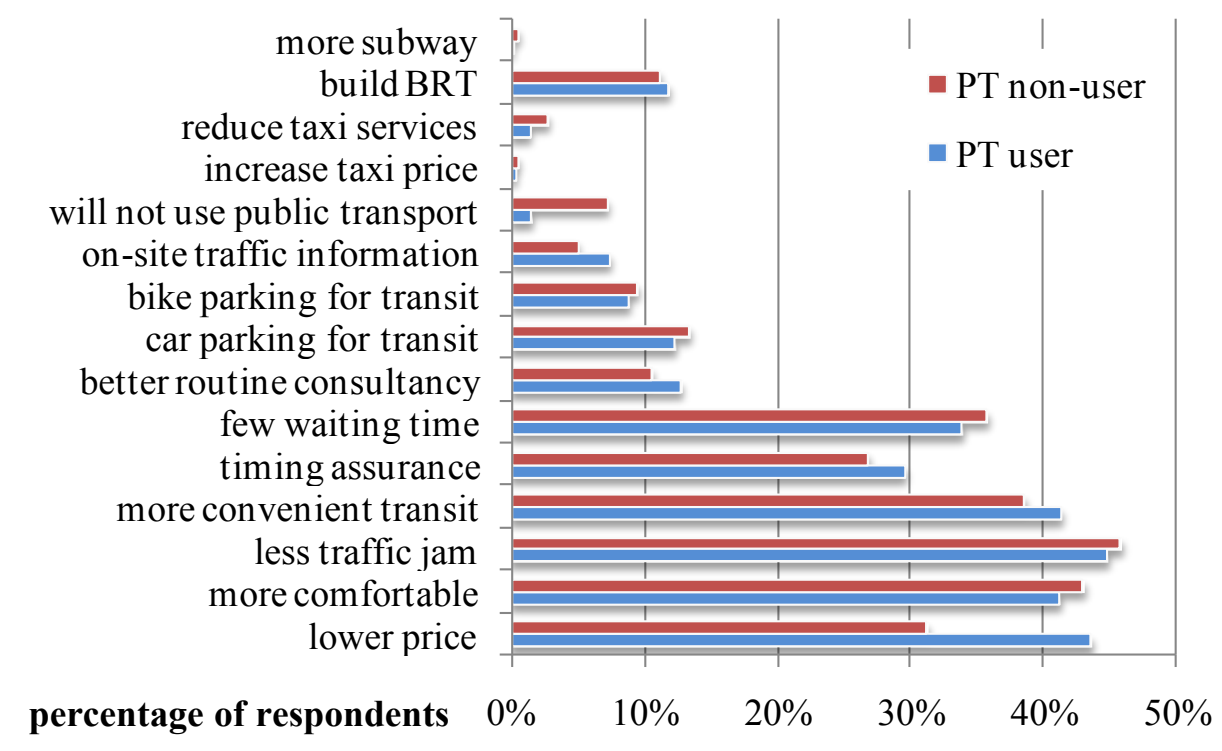

Figure AA: Which policy will increase your use of public transport in Shenzhen?

\subsection{Non-motorized Transport}

It is widely recognized that an increase in walking and cycling for short journeys in urban areas could reduce traffic congestion, improve the quality of the urban environment, promote improved personal health, and contribute to a reduction in carbon emissions (Tight et al, 2011).

Based on the trip-day survey in Shenzhen in 2014, about $5 \%$ of urban trips were made by bicycling, and $45 \%$ by walking (17\% for walking longer than 10 minutes and $28 \%$ for walking shorter than or equal to 10 minutes). Bicycling is rarely used in urban transport in Hong Kong, accounting for only $0.5 \%$ and $0.3 \%$ of trip legs in 2002 and 2011. Meanwhile, walking accounted for $39 \%$ and $35 \%$ of total trip legs in the two years.

Even though it may be calculated using slightly different definitions, we still can roughly compare the share of bicycling and walking in Shenzhen and Hong Kong with the experience of other countries. Internationally, the United States and Canada also have low levels of cycling, accounting for $1 \%$ and $2 \%$ of urban trips (Tight et al., 2011). However, some cities in the world have a much higher prevalence of bicycling and walking, including 
about one quarter of trips in the UK, $30 \%$ in Denmark, Finland, Germany, and Sweden, and close to $50 \%$ in the Netherlands (Tight et al., 2011). In the Netherlands, $28 \%$ of urban trips are by bicycling (Pucher and Dijkstra, 2000). Thus, both Hong Kong and Shenzhen are relatively behind in developing bicycling as viable travel mode.

In order to understand the characteristics of bicycle transport in Hong Kong and Shenzhen, we also analyze bicycle ownership and the trip purposes when riding bicycles. The bicycle use rate is lower than the ownership rate. In Shenzhen in 2014, 32.7\% of respondents owned bicycles but only $26.4 \%$ said they were bicycle users. In Hong Kong in 2011, 9.6\% owned bicycles, while about $9 \%$ used bicycles in the past 3 months, of which about $5 \%$ used rented bikes. In Hong Kong, the percentage of households with bicycles was much higher in rural areas such as Tai Po, North Lantau and Sha Tin. In Shenzhen, commuting to work is a major trip purpose and accounts for more than half of all the cycling trips. Based on the tripday survey, $56 \%$ of bicycle trips are for work, $22 \%$ for shopping, $8 \%$ for entertaining and social activities. In Hong Kong, due to the limited size and the slope of the road system, people mostly use bicycles for recreation and exercise.

Both Shenzhen and Hong Kong initiated bicycle renting programs. In Hong Kong, about half of the people who rented bicycles only rented on the weekend and people who own or rent bicycles tend to be younger, employed, richer and in rural areas. Shenzhen's bikerenting program has not been very successful. Shenzhen initiated several pilot projects in Shenzhenwan, Shekou, Yantian, and Xin'an areas in 2012 to test different types of bicycle renting systems. There are 18 bicycle renting service stations in Shenzhen providing more than 1000 bicycles. Only $9.2 \%$ of respondents rented a bike in the past three months, primarily (90\%) for entertainment, social activities, and exercise (see Figure xx). Only 25\% of respondents expressed willingness to rent a bike in the future. People who do not want to rent a bike say that they prefer to use public transport or motor vehicles, or they already own 
a bike (see Figure ). The bike-renting program itself also has some shortcomings; some people do not know where to rent the bikes and how to use them to transit to public transportation, which indicates that the government needs to make greater efforts to disseminate information about the bike-renting program and how to use bicycles in the parktransit scheme. Improvement in air quality also could encourage more people to rent bicycles.

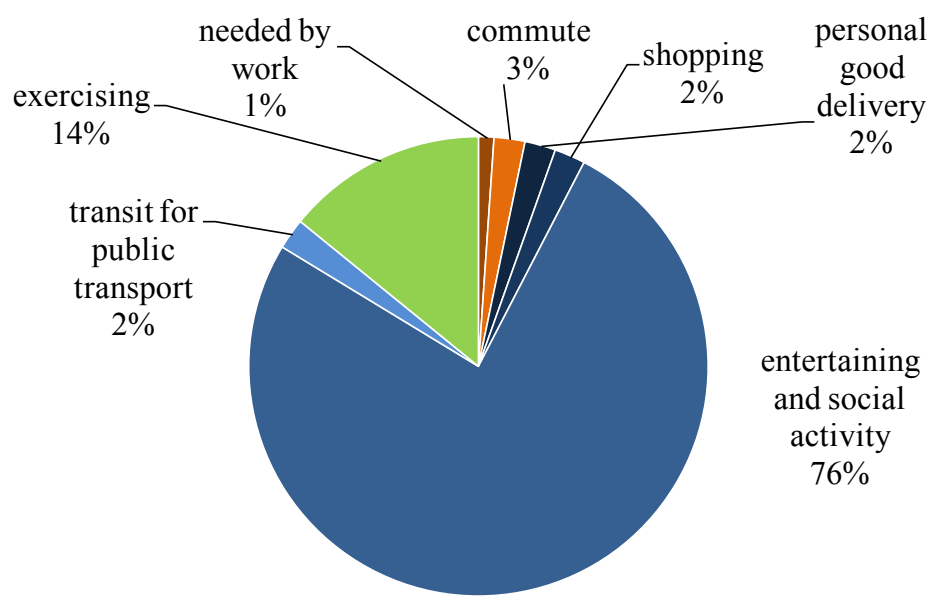

Figure CC: travel purpose of renting a bike in Shenzhen in the past three months.

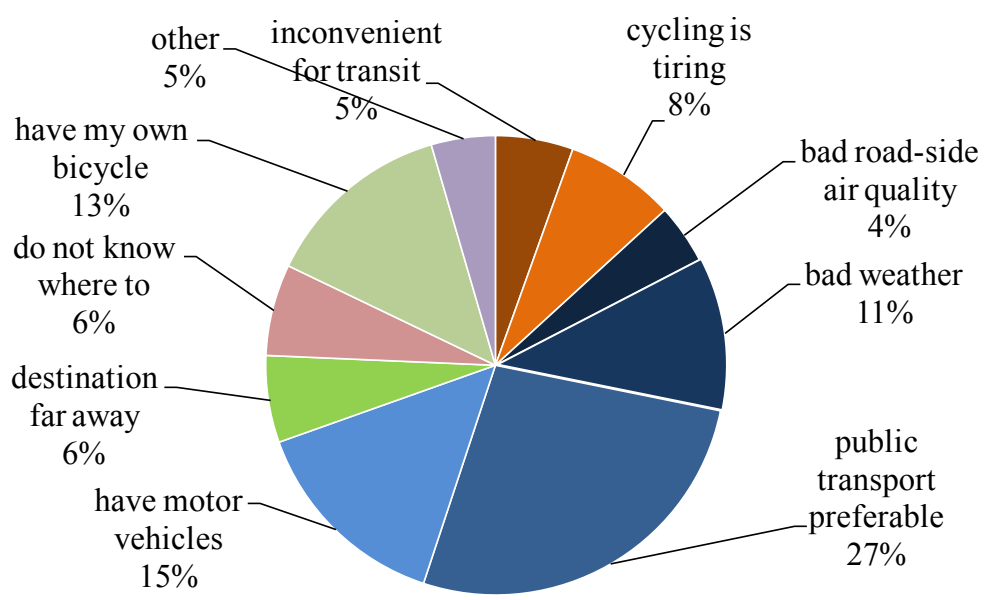

Figure DD: why won't you rent a bike in the future in Shenzhen? 
Promoting bicycling continues to face severe challenges, including competition from an improving public transport system and rising private vehicle ownership, as well as safety, environmental, and infrastructure concerns. Only about $13 \%$ of Shenzhen respondents say they may buy a bicycle in the near future. The major reasons that prevent people from buying a bicycle include features of biking itself (46\%, including safety concerns, becoming tired, limited distance), infrastructure (18\%, including bicycle lanes, park and transit facilities), air pollution problems (5\%) and other personal factors (31\%, including riding skills, already one, etc.) (see Figure ).

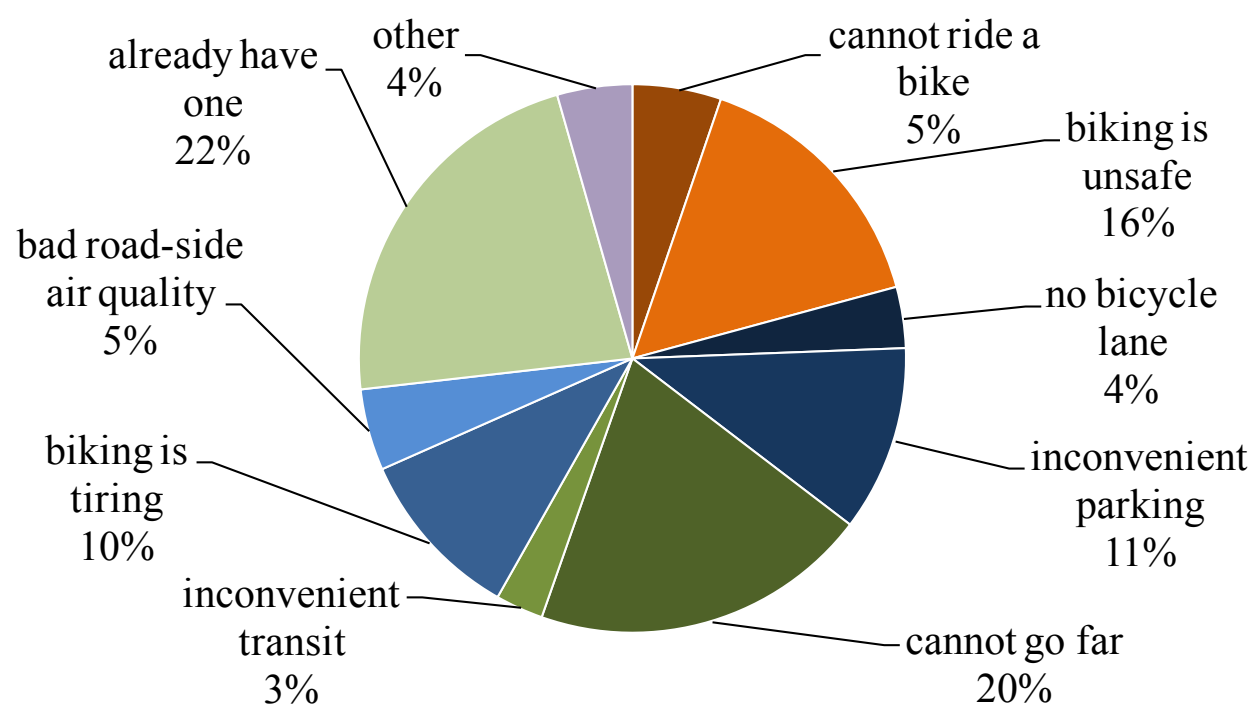

Figure EE: why won't you buy a bike in the future in Shenzhen?

\section{Conclusion}

To conclude, we highlight some of the major factors that influence individual transport behavior in Shenzhen and Hong Kong. First, public transport accounts for significantly higher proportions in the total passenger trips in Hong Kong than in Shenzhen. One important reason is the greater level of infrastructure and service supply in Hong Kong than in Shenzhen. In this respect, Shenzhen plans to catch up to the level of Hong Kong by 2030 due to the strong investment and leadership of industry by the Shenzhen government. 
Hong Kong also has managed to limit ownership and use of cars much more effectively than in Shenzhen, even at a much higher level of income per capita. They have done so by influence the cost of owning a car, by setting very high first registration tax and parking fees. For this reason, cars are very unlikely to be a competitive alternative to public transport for a majority of citizens in Hong Kong. In contrast, in Shenzhen we observe strong aspirations to own private cars among Shenzhen citizens. The share of private cars in total passenger trips in Shenzhen (15\%) is already higher than in Hong Kong (5\% in 2002 and 4\% in 2011). Shenzhen is now trying to control vehicle numbers by controlling quantity. Whether this will be successful remains an open question, as it requires effective enforcement of the restrictions which many citizens have a strong incentive to evade.

Besides ownership and use of private cars, promoting EVs is one of the most important options for reducing environmental impact of transportation. This is one area where Shenzhen appears to have done a better job than Hong Kong, as measured by both the absolute number of EVs and their share in the total vehicle population. Shenzhen's success has a lot to do with the strong role of the local government. The government has a strong influence on public transport service providers, which are usually state-owned enterprises, and provides generous subsidies to producers and consumers to encourage the production and purchase of EVs.

Neither city has done particularly well in promoting non-motorized transport, unlike some cities in the world, especially in Europe. Program to promote bicycle use have performed particularly poorly. Reversing this pattern will require much bolder approaches. 


\section{References}

An, Kang, Xiaohong Chen, Feifei Xin, Bin Lin, and Longyu Wei. 2013. "Travel Characteristics of E-Bike Users: Survey and Analysis in Shanghai." Procedia - Social and Behavioral Sciences 96: 1828-1838.

Choi, Jinmu, Won Do Lee, Woon Ho Park, Chansung Kim, Keechoo Choi, and ChangHyeon Joh. 2014. "Analyzing Changes in Travel Behavior in Time and Space using Household Travel Surveys in Seoul Metropolitan Area Over Eight Years." Travel Behaviour and Society 1 (1): 3-14.

de Sá, Thiago Hérick, Diana C. Parra, and Carlos Augusto Monteiro. 2015. "Impact of Travel Mode Shift and Trip Distance on Active and Non-Active Transportation in the São Paulo Metropolitan Area in Brazil." Preventive Medicine Reports 2: 183-188.

Dillon, Harya S., Jean-Daniel Saphores, and Marlon G. Boarnet. 2015. "The Impact of Urban Form and Gasoline Prices on Vehicle Usage: Evidence from the 2009 National Household Travel Survey." Research in Transportation Economics 52: 23-33.

Nitsche, Philippe, Peter Widhalm, Simon Breuss, Norbert Brändle, and Peter Maurer. 2014. "Supporting Large-Scale Travel Surveys with Smartphones - A Practical Approach." Transportation Research Part C: Emerging Technologies 43, Part 2: 212-221.

Pasaoglu, Guzay, Alyona Zubaryeva, Davide Fiorello, and Christian Thiel. 2014. "Analysis of European Mobility Surveys and their Potential to Support Studies on the Impact of Electric Vehicles on Energy and Infrastructure Needs in Europe." Technological Forecasting and Social Change 87: 41-50.

Zhou, Jiangping. "The Transit Metropolis of Chinese Characteristics? Literature Review, Interviews, Surveys and Case Studies." Transport Policy.

An, K., Chen, X.H., Xin, F.F., Lin, B., Wei, L.Y., 2013. Travel characteristics of e-bike users: Survey and analysis in Shanghai. Procedia - Social and Behavioral Sciences, 96, 18281838.

BTRC (Beijing Transportation Research Centre), 2011. Annual Report of Beijing's Transportation Development (in Chinese). BTRC, Beijing.

$<$ http://www.bjtrc.org.cn/JGJS.aspx?id=5.2\&Menu=GZCG $>$ (accessed 02.12).

Choi, J.M., Lee, W.D., Park, W.H., Kim, C.S., Choi, K.C., Joh, C.H., 2014. Analyzing changes in travel behavior in time and space using household travel survey in Seoul metropolitan area over eight years. Travel Behavior and Society, 1, 3-14.

Dantzig, G.B., Saaty, T. L., 1973. Compact City: Plan for a Liveable Urban Environment. San Francisco: W. H. Freeman.

Department of Transportation, U.S. (DOT), 2011. Summary of Travel Trends - 2009 National Household Travel Survey. Virginia: National Technical Information Service, Springfield Virginia 22161.

Gini, C., 1909. Concentration and dependency ratios (in Italian). English translation in Rivista di Politica Economica, 87 (1997), 769-789.

Hu, XW., Wang, J., Wang, L., 2013. Understanding the travel behavior of elderly people in the developing country: as case study of Changchun, China. Procedia - Social and Behavioral Sciences, 96, 873-880. 
Manoja and Vermab, 2013. Analysis and modeling of activity-travel behavior of non-workers from a city of developing country, India. Procedia - Social and Behavioral Sciences, 104, 621-629.

Maslow, A.H., 1943. A theory of human motivation. Psychological Review, 50 (4), 370-96. Retrieved from http://psychclassics.yorku.ca/Maslow/motivation.htm [last access on 20150629]

National Statistic Bureau (NBS), 2014. Chinese Statistic Yearbook 2014. Beijing: Chinese Statistic Press.

Statistic Bureau of Shenzhen (SBS), 2014. Shenzhen Statistic Yearbook 2014. Beijing: Chinese Statistic Press.

SBS, 2015. Shenzhen 2014 National Economic and Social Development Statistics Bulletin. Available from: http:/www.sztj.gov.cn/xxgk/tjsj/tjgb/201504/t20150424 2862885.htm [last access on 20150626]

Wooldridge, J.M.. 2009. Introductory Econometrics (4th edition). Canada: Macmillan Publishing Solutions.

Xianyu, J.C., 2013. An exploration of the interdependencies between trip chaining behavior and travel mode choice. Procedia - Social and Behavioral Sciences, 96, 1967-1975.

Zhen J.X., 2013. Development strategy for constructing comprehensive bicycle transport system in Shenzhen (in Chinese). Qingdao: Annual National Planning Conference 2013, Urban Planning Society of China. 